\title{
Site-specific distribution of the bivalve Scrobicularia plana along the European coast
}

\author{
Sílvia Santos $^{1, *}$, Geert Aarts ${ }^{1,2}$, Pieternella C. Luttikhuizen ${ }^{1}$, Joana Campos ${ }^{3}$, \\ Theunis Piersma ${ }^{1,4}$, Henk W. van der Veer ${ }^{1}$
}

${ }^{1}$ NIOZ - Royal Netherlands Institute for Sea Research, PO Box 59, 1790 AB Den Burg Texel, The Netherlands

${ }^{2}$ Wageningen IMARES- Institute for Marine Resources and Ecosystem Studies, PO Box 68, 1970 AB IJmuiden, The Netherlands

${ }^{3}$ CIMAR/CIIMAR - Centro Interdisciplinar de Investigação Marinha e Ambiental — Universidade do Porto, Rua dos Bragas, 289, 4050-123 Porto, Portugal

${ }^{4}$ Animal Ecology Group, Centre for Ecological and Evolutionary Studies, University of Groningen, PO Box 11103 , 9700 CC Groningen, The Netherlands

\begin{abstract}
The development and maintenance of spatial patterns and the way they affect the dynamics of populations and ecosystems is a key issue in ecology. Since each individual and each species experiences the environment on a unique range of scales, it is vital to determine the spatial scales across which organisms interact with each other and the structuring influence of their environments, which can be achieved by analyzing species' distribution patterns. Here, the spatial variation in the distribution of Scrobicularia plana is described for 4 intertidal areas along the species' distributional range. Spatial autocorrelation correlograms based on Moran's coefficient reveal that while the Trondheim (Norway) population was randomly distributed, at Minho (Portugal), the Westerschelde, and the Wadden Sea (both in The Netherlands) populations were aggregated. Patch diameter varied from 150 to $1250 \mathrm{~m}$, in Minho and Westerschelde, respectively; while in the Wadden Sea, patches of 4 to $10 \mathrm{~km}$ were detected. Comparisons of spatial patterns with those of other co-occurring bivalve species (Abra tenuis, Cerastoderma edule, and Macoma balthica) revealed that $S$. plana's distribution was generally patchier. The distribution of $S$. plana was correlated with sediment type at Westerschelde and Trondheim, but not Minho. The observed differences in distribution patterns and their correlation with environmental factors reveal that spatial patterns of $S$. plana are site-specific rather than species-specific.
\end{abstract}

KEY WORDS: Distribution · Intertidal $\cdot$ Larval settlement $\cdot$ Moran's $I \cdot$ Patchiness $\cdot$ Sediment type $\cdot$ Spatial autocorrelation analysis

Resale or republication not permitted without written consent of the publisher

\section{INTRODUCTION}

Intertidal mudflats are valuable ecological entities that support large populations of birds (e.g. Beukema et al. 1993, Zwarts \& Wanink 1993, Ens et al. 1994, Leguerrier et al. 2003, van de Kam et al. 2004), and act as nursery and feeding areas for fish and crustaceans (Martinho et al. 2007, Campos et al. 2010). Macrobenthic communities are key elements of intertidal ecosystems, playing an important role in the food web and system dynamics (Herman et al. 1999). Spatial patterns of macrobenthic invertebrates are shaped not only by environmental variation, but also by biotic interactions among species and the diversity of the assemblages (Underwood et al. 2000). Identification and quantification of spatial patterns at several spatial and/or temporal scales are, therefore, essential to help understand the factors and processes shaping these soft-sediment communities (Ellis \& Schneider 2008), a prerequisite for a sound 
implementation of integrated management, as it will allow for better predictions regarding communities' responses to future environmental changes.

The spatial pattern of a population is the result of a balance between dispersal and aggregation (Heip 1975, Meire et al. 1989, Folmer et al. 2010). Spatial patterns can be characterized by 2 aspects: intensity and form (Andrew \& Mapstone 1987). Intensity, which relies on the distribution of density estimates, sorts distributions into 3 types: uniform, random, and aggregated (Meire et al. 1989, Thrush et al. 1989, Thrush 1991). A uniform pattern means that individuals are arranged in a regular way, likely due to intraspecific competition; while in the random pattern the space occupied by an individual is independent of the space occupied by others. In the aggregated pattern, individuals are clumped together as a result of environmental heterogeneity, predation pressure, competition or reproductive behavior (Heip 1975, Meire et al. 1989). As for the form of the spatial pattern, it corresponds to the size of patches and can be assessed with spatial autocorrelation which analyzes the degree of dependency among observations in relation to the arrangement of individuals in space (Thrush et al. 1989, Thrush 1991, Kraan et al. 2009).

Since the majority of natural environments are patchy and environmental heterogeneity tends to cause aggregated distributions, most populations are aggregated to some extent (Levinton 1972, Heip 1975, Barry \& Dayton 1991, Kraan et al. 2009). Spatial aggregation can occur on different scales, e.g. from the geographical distribution of a species to the physical structure of the sediment (de Wolf 1989, Underwood \& Chapman 1996, Kraan et al. 2010) and, as a consequence, ecological variables and processes tend to be scale-dependent (Legendre \& Fortin 1989). Since organisms may respond to more than one of these levels (Hewitt et al. 1996), analysis of the hierarchical structure of factors affecting patchiness is essential to understand its responses.

Highly patchy spatial distributions are typical for many hard substrate invertebrates and also, for example, reef forming bivalves such as mussels, while soft bottom infauna is generally more evenly distributed (Meire et al. 1989). Nevertheless, a patchy distribution has been recorded in several codistributed soft bottom bivalves such as Mya arenaria (Strasser et al. 1999, Bocher et al. 2007), Macoma balthica, and Cerastoderma edule (Meire et al. 1989, Kraan et al. 2009), and Scrobicularia plana (Hughes 1970, Langston 1986). Local distribution patterns of intertidal molluscs, however, may vary between sites and only by comparing the spatial patterns from different areas can we determine if patterns are species- or site-specific (Bocher et al. 2007). While species-specific patterns suggest that spatial distributions are mainly determined by the characteristics of the species, site-specific patterns must be explained by interactions between species' characteristics and local factors. The later, therefore, emphasizes the need for site-specific studies for a better understanding of the factors determining the observed spatial patterns.

Here, we focus on the peppery furrow shell Scrobicularia plana, a common species in European intertidal soft-sediment communities (Bocher et al. 2007). S. plana seems to be characterized by an overall patchy distribution (Hughes 1970, Langston 1986), which appears to be determined by the existence of specific environmental conditions during settlement (Santos et al. 2011b). The species is an important food source for shorebirds and fish (e.g. Hughes 1970, Moreira 1997), and economically valuable, especially in southern Portugal and Spain (Langston et al. 2007). The species is present along the NE Atlantic coast, from the Norwegian and Baltic Seas in the north to Senegal in the south, and in the Mediterranean Sea (Tebble 1976). Although it can be found in areas of sand, clay or mud, rich in organic matter, it has a clear preference for muddy sediments (Casagranda \& Boudouresque 2005, Bocher et al. 2007).

To determine whether the species' distribution is a species- or site-specific trait, we analyzed the spatial distribution of Scrobicularia plana, as well as several co-distributed bivalve species, at 4 sites and 2 spatial scales. Such descriptive results serve as a basis for hypotheses regarding the factors and processes determining the observed spatial structure, they can then be put to a test with additional observations and experimental approaches.

\section{MATERIALS AND METHODS}

\section{Field sampling}

Distributions and densities of benthic bivalves were determined for 3 smaller-scale intertidal areas along the European coast: Minho, Portugal (41 $\left.{ }^{\circ} 51-52^{\prime} \mathrm{N}, 08^{\circ} 49-50^{\prime} \mathrm{E}\right)$; Westerschelde, The Netherlands $\left(51^{\circ} 20-21^{\prime} \mathrm{N}, 03^{\circ} 42-44^{\prime} \mathrm{E}\right)$; and Trondheim, Norway $\left(63^{\circ} 18-19^{\prime} \mathrm{N}, 10^{\circ} 09-11^{\prime} \mathrm{E}\right)$, as well as one larger-scale area, the Dutch Wadden Sea (Fig. 1). In order to estimate temporal changes and spatial differences in abundance, while accurately estimating model autocorrelation parameters, the most effective 
sampling design was a grid with additional random samples placed on the gridlines (Bijleveld et al. 2012). The distance between points varied between locations according to the total area of the sampling sites. In addition to the regular grid, 10\% (Wadden Sea) to $25 \%$ (remaining 3 locations) extra cores were collected at random positions to account for autocorrelations at smaller distances (for the rationale of this approach, see Bijleveld et al. 2012). Description of the dimensions and number of points sampled in each grid can be found in Table 1.

At each sample point, identified using GPS coordinates, a sediment core (15 cm diameter, to a depth of 20$25 \mathrm{~cm}$ ) was taken. The core samples were sieved, on site, over a $1 \mathrm{~mm}$ mesh and all organisms were collected and stored at $-20^{\circ} \mathrm{C}$ for later analysis. A second core $(6 \mathrm{~cm}$ diameter, to a depth of $5 \mathrm{~mm}$ ) was taken in order to determine grain size composition of the sediment surface layer. Samples were stored at $-20^{\circ} \mathrm{C}$ until further analysis.

\section{Laboratory analyses}

All bivalves collected were identified and counted. Sediment samples were freeze-dried (Christ Alpha 1-4 LD plus) and then treated to remove organic matter and carbonate material, as described by Van den Bergh et al. (2003). Analysis of median particle size and the percentage of silt (fraction $<63 \mu \mathrm{m}$ ) of sediment samples was performed using a Coulter LS 13320 particle size analyzer and autosampler.

\section{Statistical analyses}

The analyses were performed in 2 steps. Smallscale patchiness of Scrobicularia plana and a number of co-occurring bivalve species was analyzed for Minho, Westerschelde and Trondheim. A largerscale analysis for $S$. plana was conducted in the Dutch Wadden Sea.

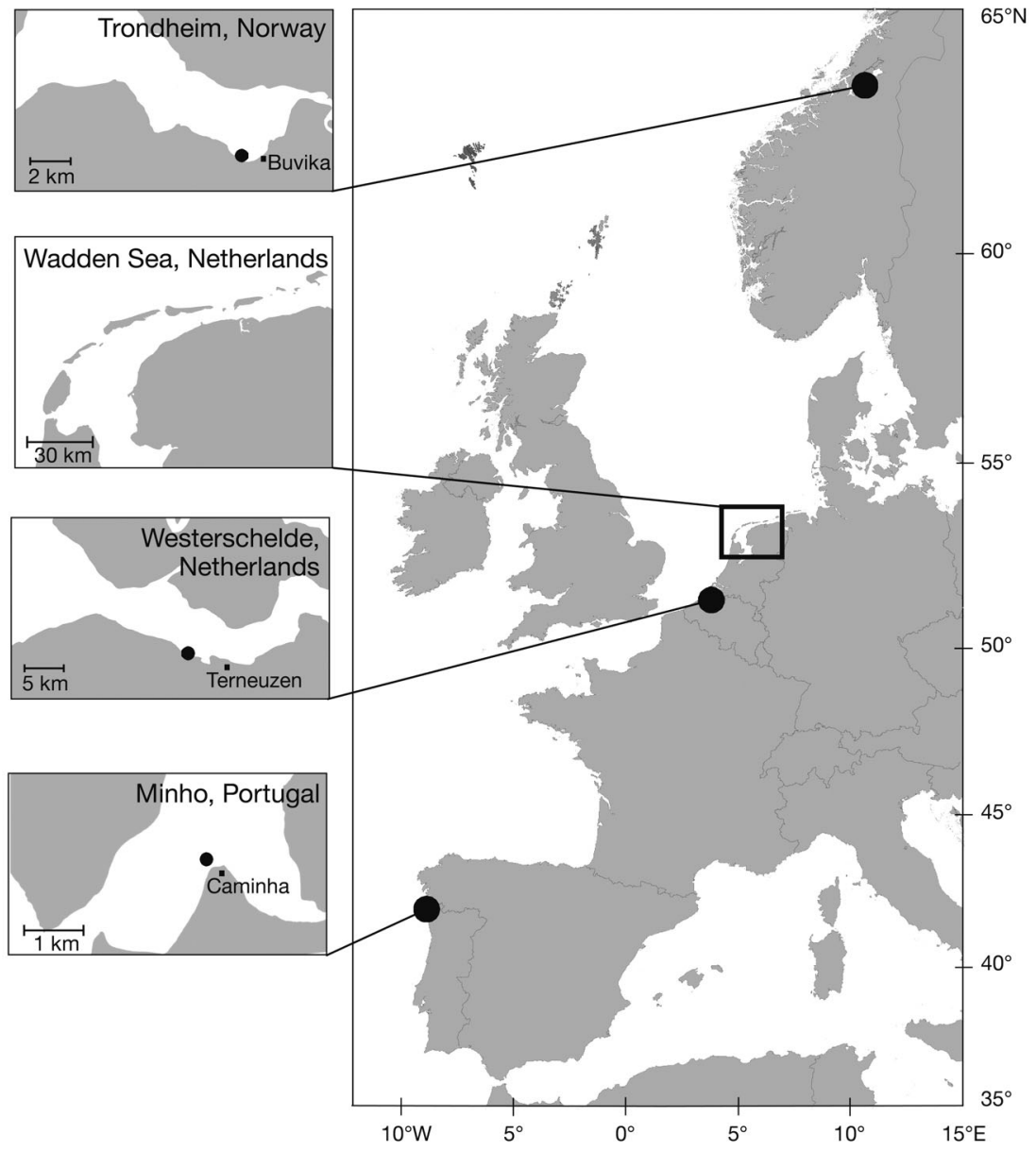

Fig. 1. Sampling locations of Scrobicularia plana along the European coast

Table 1. Dimensions and number of points sampled in each sampling grid. Number of sample points corresponds to total number of points sampled, i.e. including regular grid points as well as $\sim 10 \%$ (Wadden Sea) to $25 \%$ (remaining 3 locations) of randomly placed points along the gridlines

\begin{tabular}{|lcccccc|}
\hline Location & Year & $\begin{array}{c}\text { Grid length } \\
\text { (easting, } \mathrm{km})\end{array}$ & $\begin{array}{c}\text { Grid width } \\
(\text { northing, km) }\end{array}$ & $\begin{array}{c}\text { Total area } \\
\left(\mathrm{km}^{2}\right)\end{array}$ & $\begin{array}{c}\text { Distance between } \\
\text { points }(\mathrm{m})\end{array}$ & $\begin{array}{c}\text { No. of sample } \\
\text { points }\end{array}$ \\
\hline Minho, Portugal & 2009 & 1.6 & 1.6 & 2.6 & 50 & 137 \\
Westerschelde, The Netherlands & 2009 & 3.2 & 1 & 3.2 & 100 & 161 \\
Wadden Sea, The Netherlands & 2008 & - & - & 1500 & 500 & 4376 \\
& 2009 & - & - & 1500 & 500 & 4771 \\
Trondheim, Norway & 2008 & 1.3 & 0.7 & 0.9 & $50 \times 100^{\mathrm{a}}$ & 79 \\
aEach point was sampled at a distance of 50 m northward and 100 m eastward & & \\
\hline
\end{tabular}


Distribution and density were plotted using the ggplot2 Package (Wickham 2009), in R v. 2.13.1. Spatial autocorrelation (SAC) between abundance and distance was calculated for Abra tenuis, Cerastoderma edule, Macoma balthica, Mya arenaria, and Scrobicularia plana using Moran's index $(I)$, also in R. This index compares geographic neighbors in terms of their deviation from the mean of all observations, estimating an autocorrelation coefficient that varies between -1.0 (negative autocorrelation) and 1.0 (positive autocorrelation), with values near zero indicating no spatial autocorrelation. Where correlations are found, the cross point of the zero line is considered a rough measure of patch diameter.

Partitioning geographic distances into discrete a priori classes must be evaluated. Classes containing too few pairs of locations will produce less reliable Moran's I values, whereas coarser classes (encompassing a larger increment of geographic distance), while statistically reliable, will sacrifice resolution of the actual distance (patch) size. The number of distance classes (or lags) was calculated using Sturges' rule (Sturges 1926). The width of each distance class was determined as the maximum geographic distance divided by 2 (Rossi et al. 1992) and then subdivided by the number of distance classes. Once distance classes were determined, significance was tested by a Monte Carlo randomization test with 999 permutations, under a one-tailed test for positive autocorrelation (Legendre \& Legendre 1998), using the spdep R Package (Bivand et al. 2011). As the pattern of a correlogram may be affected by the lag distances selected, the consistency of patterns was tested by altering the lag distance.

Correlograms, in which Moran's I coefficients are plotted against spatial distances, were generated in the ncf $\mathrm{R}$ package (Bjornstad 2009). Correlograms were globally significant only when at least one of its Moran's $I$ values was significant at the Bonferroni corrected level (Oden 1984, Legendre \& Legendre 1998). Within each correlogram, the significance of Moran's I for each distance class was tested using Holm's correction for multiple comparisons (Holm 1979). A requirement for this analysis is second-order stationarity, i.e. the mean and variance are constant and the autocorrelation function depends only on the distance between observations (Legendre \& Legendre 1998). Therefore, in order to stabilize the mean and variance and avoid deviations that may result in violation of stationarity, frequency data were logtransformed $x^{\prime}=\log (x+1)$ prior to analysis (Zar 1996).

The relationship between sediment type, i.e. median particle size and the percentage of silt (fraction
$<63 \mu \mathrm{m})$, and the distribution of Scrobicularia plana was determined with a partial Mantel test (Mantel 1967) implemented in the cluster (Maechler et al. 2011) and vegan (Oksanen et al. 2011) R packages. Significance was tested using 10000 permutations. Probability levels were adjusted using the False Discovery Rate (FDR) correction procedure (Benjamini \& Hochberg 1995), which controls the expected proportion of incorrectly rejected null hypotheses (type I errors).

\section{RESULTS}

\section{Distribution and spatial autocorrelation in Scrobicularia plana}

The numerical distribution of Scrobicularia plana over the 3 smaller-scale sampling sites (Fig. 2) shows that densities (means \pm SE) varied between $43 \pm$ 5.49 ind. $\mathrm{m}^{-2}$, in $\mathrm{f}$ to $72 \pm 13.81$ ind. $\mathrm{m}^{-2}$, in Trondheim; while a value of $56 \pm 6.87$ ind. $\mathrm{m}^{-2}$ was registered for the Westerschelde.

The SAC analysis determined the number of distance classes calculated for each sampling site which varied only slightly, with 13 in Trondheim, 14 in Minho, and 15 in the Westerschelde. Lag distance was defined as 75, 114, and $60 \mathrm{~m}$, for Minho, Westerschelde and Trondheim, respectively. A distancebased, spatial weights matrix was created for each location, using the defined lag distance as the upper distance bound. Only lags including $>30$ pairs of points were considered (Rossi et al. 1992) and, as a result, while all 15 lags were included in the analysis at Westerschelde, lags 14 for Minho and 7-13 for Trondheim were not analyzed. Tests of significance of the Moran's I for each lag revealed that, for Scrobicularia plana, lags 1, 2, 6, 8, 12, and 13 from Minho had a significant positive correlation coefficient. For the Westerschelde, lags 1-11 were significantly correlated, while in Trondheim only lag 5 was significant.

Correlograms of Scrobicularia plana (Fig. 3) were globally significant at the Bonferroni corrected level for Minho and Westerschelde, which indicates that the species is patchily distributed at these locations, but not for the Trondheim sampling site. Indeed, densities showed positive autocorrelations at the smallest distance-classes, followed by random oscillations around zero and, in some cases, significantly negative correlation (i.e. dissimilar values appear in close association). S. plana in Minho was spatially correlated up to a distance of $150 \mathrm{~m}$. In the Westerschelde, positive spatial correlation was observed for dis- 

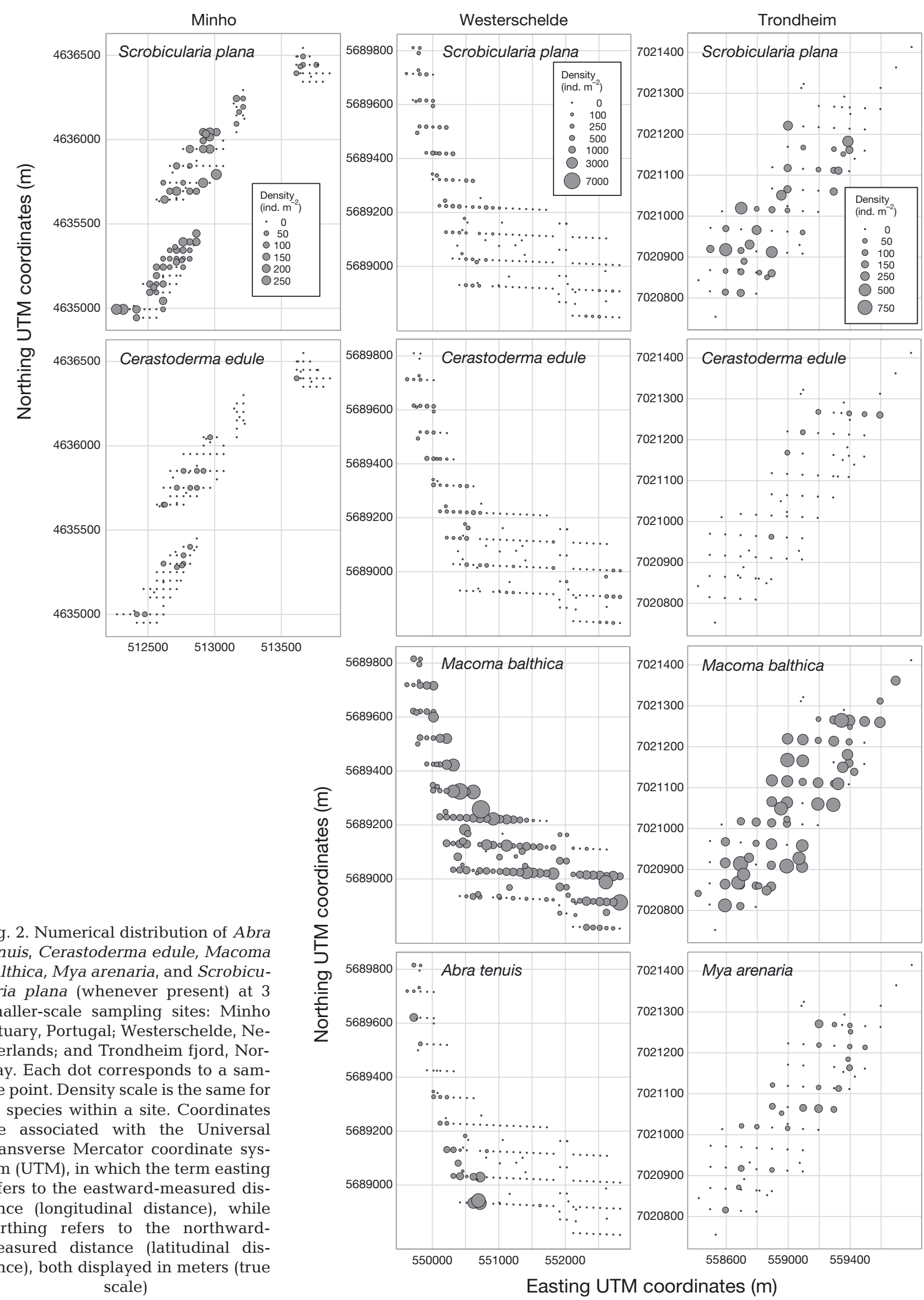

Fig. 2. Numerical distribution of Abra tenuis, Cerastoderma edule, Macoma balthica, Mya arenaria, and Scrobicularia plana (whenever present) at 3 smaller-scale sampling sites: Minho estuary, Portugal; Westerschelde, Netherlands; and Trondheim fjord, Norway. Each dot corresponds to a sample point. Density scale is the same for all species within a site. Coordinates are associated with the Universal Transverse Mercator coordinate system (UTM), in which the term easting refers to the eastward-measured distance (longitudinal distance), while northing refers to the northwardmeasured distance (latitudinal distance), both displayed in meters (true scale)
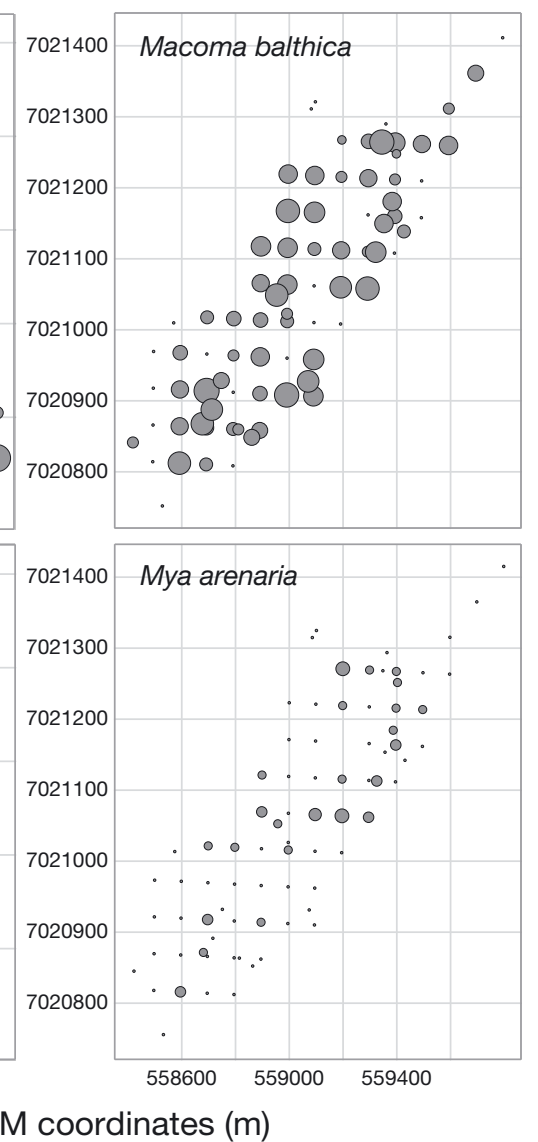


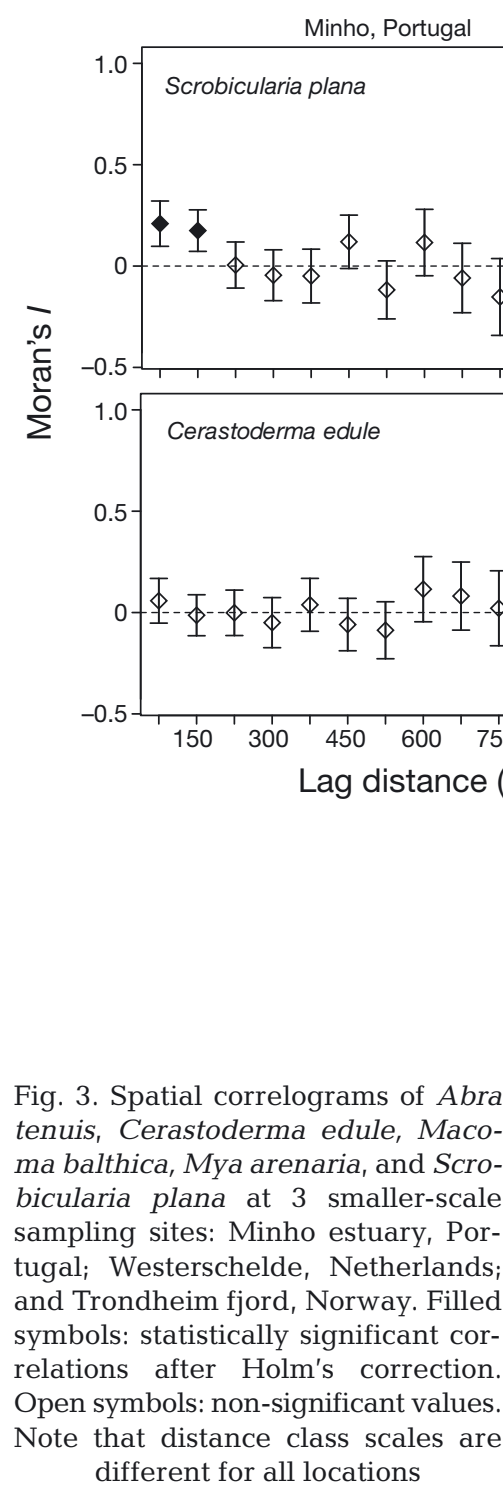

Westerschelde, Netherlands
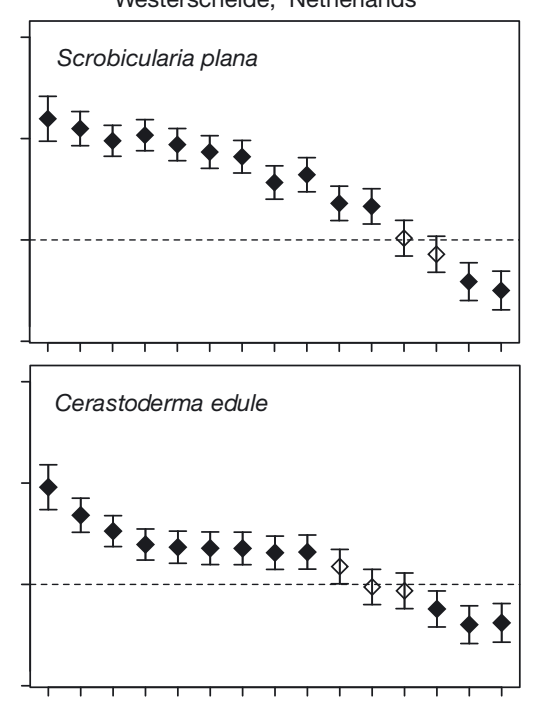
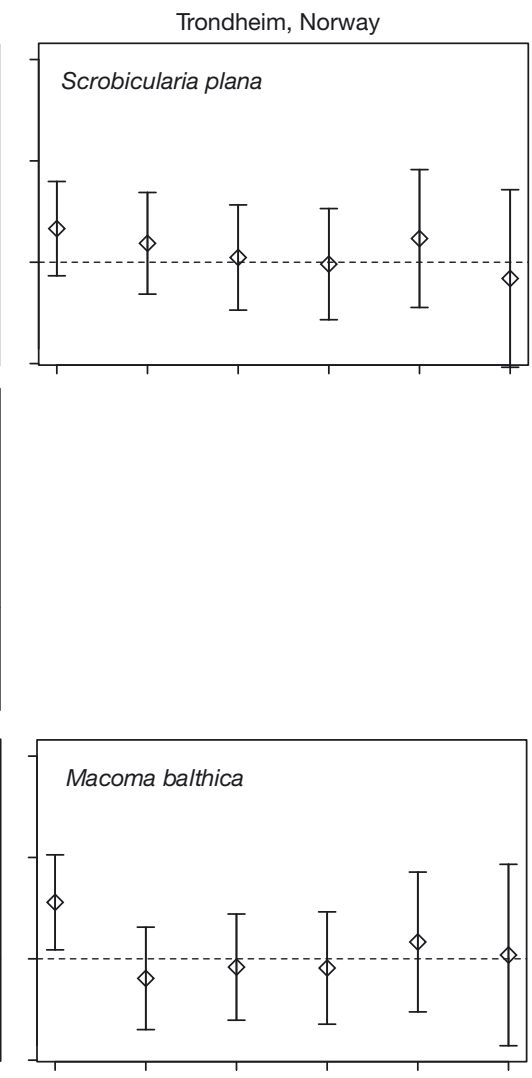

900
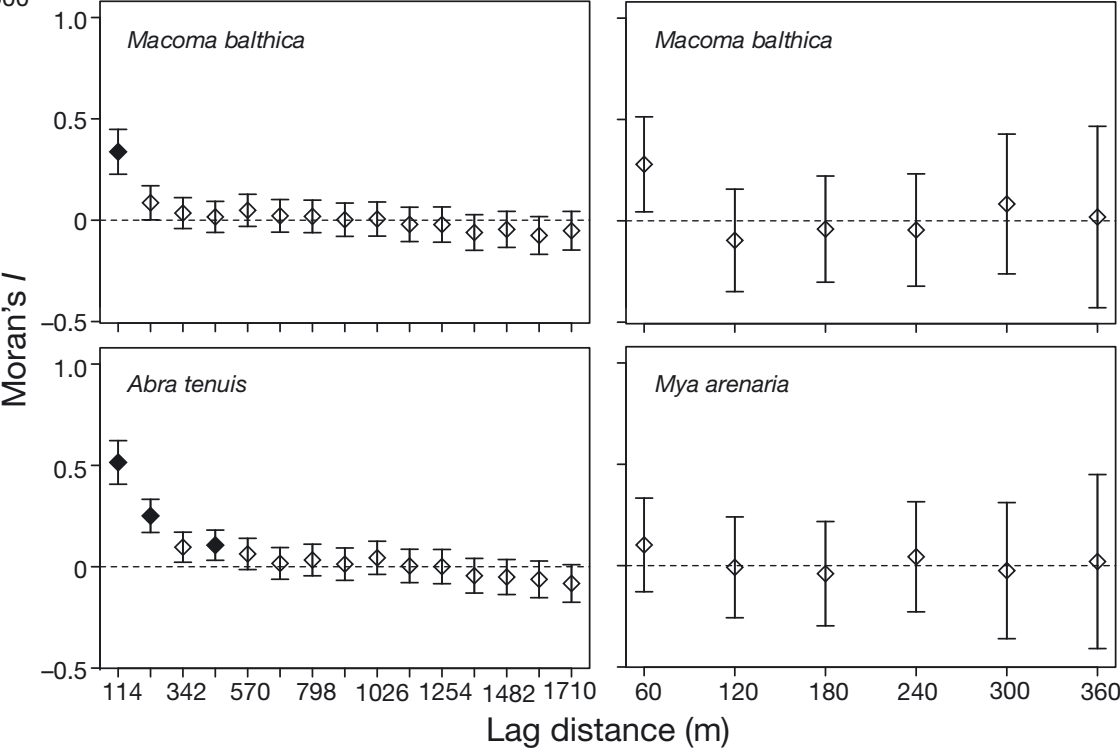

tances up to $\sim 1250 \mathrm{~m}$, while significantly negative correlation was detected at distances $>\sim 1600 \mathrm{~m}$. No spatial correlation was found for $S$. plana in Trondheim. Lag distances of 50 and $100 \mathrm{~m}$ for Minho and Trondheim, and of 100, 150, and $200 \mathrm{~m}$ for Westerschelde were tested, with no changes on the patterns in the correlograms.

The larger-scale analysis of the Wadden Sea data provided information on SAC of Scrobicularia plana, while the comparative sampling over $2 \mathrm{yr}$ also provided an indication of pattern stability and uniformity (Fig. 4). Twenty-four lags were defined at $1 \mathrm{~km}$ distances. Moran's $I$ values were statistically significant for lags $1-6,8,10-11$, and 15-24 in 2008, and only lags 1-3 in 2009. Correlograms were globally significant at the Bonferroni corrected level (Fig. 5). After
Holm's correction, positive correlation was observed for distances of up to $6 \mathrm{~km}$, with a second patch between 10 and $11 \mathrm{~km}$ in 2008, and at distances $<4 \mathrm{~km}$ as well as at $24 \mathrm{~km}$ in 2009 . However, patterns were not stable when lag distances were changed. Considering a lag distance of $2 \mathrm{~km}$, a single patch was detected in 2008 at distances of up to $10 \mathrm{~km}$; while for 2009, 2 patches were detected at up to 4 and $14 \mathrm{~km}$, respectively.

\section{Distribution and spatial autocorrelation of other species}

SAC analyses (Fig. 3) of the distribution of cooccurring bivalve species (Fig. 2) revealed that Abra 


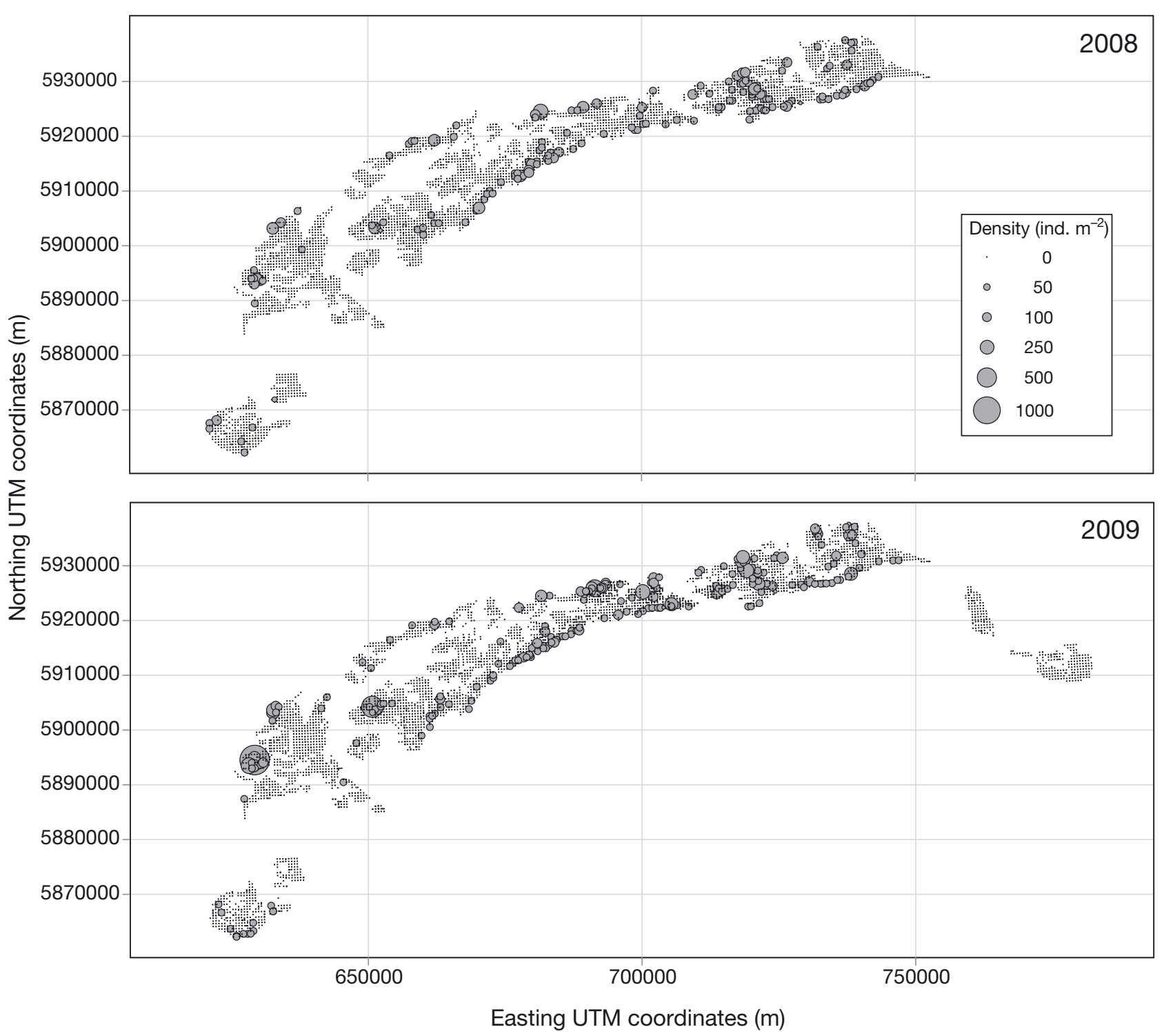

Fig. 4. Scrobicularia plana. Numerical distribution in the Dutch Wadden Sea. Each dot corresponds to a sample point. Density scale is the same for both years. See Figs. 1 \& 2 for location of the Wadden Sea within the Netherlands and explanation of UTM coordinates, respectively

tenuis, which was only found in the Westerschelde, showed a significant correlation coefficient for lags 1-2. For Cerastoderma edule, lag 8 and lags 1-10 were significant in Minho and the Westerschelde, respectively. C. edule was also found in Trondheim, but was not included in the analysis given the extremely low densities. Macoma balthica was present in the Westerschelde where lags 1-3 were significant, and in Trondheim where it showed no correlation at all. Finally, no significant correlations were found for Mya arenaria in Trondheim. In Trondheim ( $M$. balthica and $M$. arenaria) and in Minho (C. edule), correlograms were non-significant, which indicates a random distribution. In contrast, all bivalve species in the Westerschelde showed globally significant correlograms. For these, a patch size of $1000 \mathrm{~m}$ was observed for $C$. edule, while smaller patches of $115 \mathrm{~m}$ and up to $230 \mathrm{~m}$ were observed for $M$. balthica and $A$. tenuis, respectively.

\section{Relationship with sediment type}

No significant correlation was observed between sediment type and the spatial distribution of Scrobicularia plana in Minho. Significant values were found 


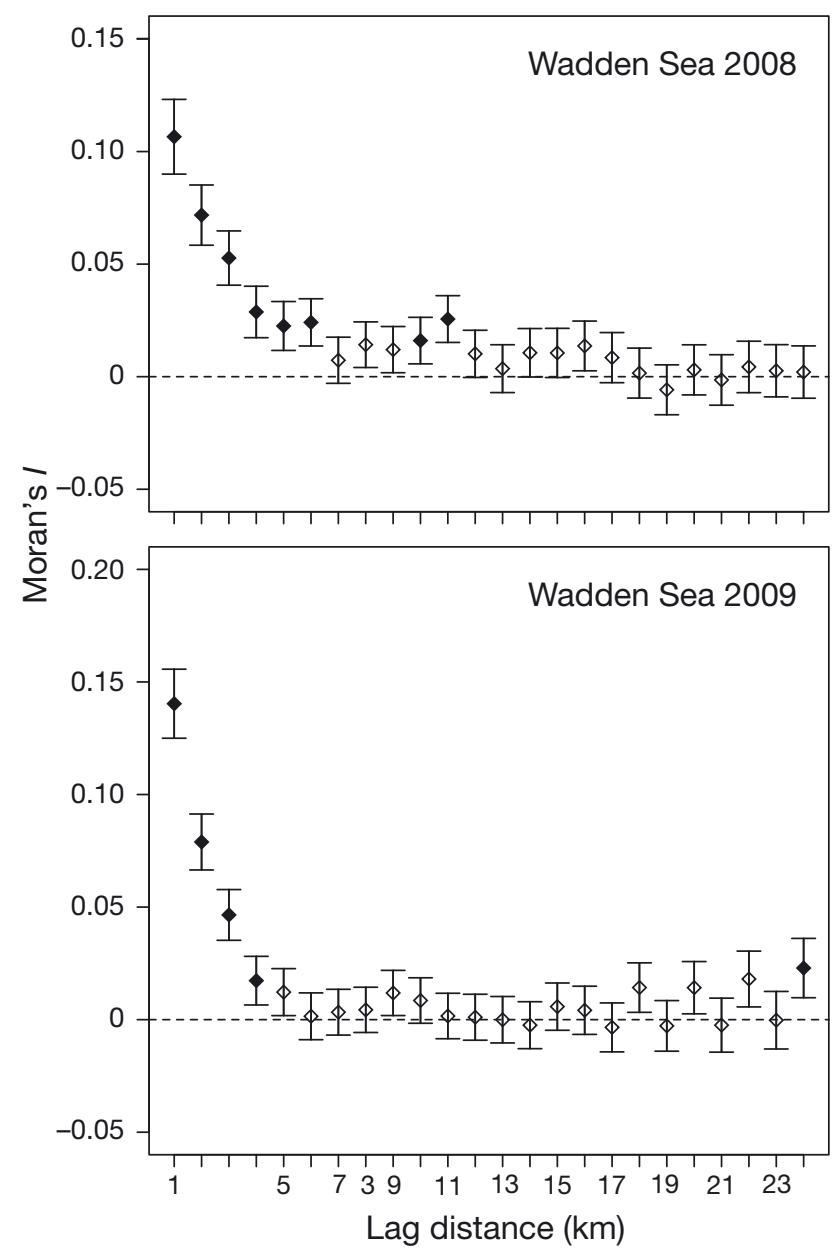

Fig. 5. Scrobicularia plana. Spatial correlograms in the Dutch Wadden Sea. Filled symbols: statistically significant correlations after Holm's correction. Open symbols: nonsignificant values

with both median particle size and percentage of silt in Westerschelde, and for percentage of silt in Trondheim (Table 2).

\section{DISCUSSION}

This study has provided insight into the small to large scale spatial patterns of Scrobicularia plana at 4 different sites along the species' distributional range. While in Minho and Westerschelde individuals showed an aggregated pattern, the Trondheim population was randomly distributed. These findings confirm previous statements (Hughes 1970, Langston 1986) that $S$. plana is characterized by patchy distributions.

A key point of the study was to analyze the shape of the correlogram since it is associated with particu-
Table 2. Partial Mantel test correlation coefficients (r) between sediment variables and frequency of Scrobicularia plana at 3 small-scale sampling locations. Probabilities have been FDR corrected and are expressed as: ${ }^{* * *} p<0.0003$; ${ }^{* *} \mathrm{p}<0.0033 ;{ }^{*} \mathrm{p}<0.0167$

\begin{tabular}{|llc|}
\hline Location & Sediment variable & $\mathrm{r}$ \\
\hline Minho, PT & Median particle size & 0.028 \\
& Percentage of silt & -0.058 \\
Westerschelde, NL & Median particle size & $0.176^{* * *}$ \\
& Percentage of silt & $0.191^{* * *}$ \\
Trondheim, NO & Median particle size & -0.019 \\
& Percentage of silt & $0.228^{* *}$ \\
\hline
\end{tabular}

lar types of spatial structures (Legendre \& Fortin 1989). Results demonstrated that the spatial distribution of Scrobicularia plana varied between locations. The random pattern observed for the Trondheim population was also detected in a previous study in the Oosterschelde, The Netherlands (Meire et al. 1989). However, most populations appear to have some degree of aggregation. In Minho, positive autocorrelations at the smallest distances, with nonsignificant random variation from $\sim 200 \mathrm{~m}$ onwards, suggested the presence of differently sized random patches (Kraan et al. 2009). This pattern is similar to the one detected in a population in north Wales (Hughes 1970), as well as the one inferred from the Westerschelde correlogram, with the difference being that negative values were observed at greater distances. The latter is the most commonly observed pattern for natural populations in which nearby sites have similar values and the most dissimilar localities are farthest apart (Sokal \& Oden 1978). However, when increasing lag distance to $250 \mathrm{~m}$, which allowed the coverage of a much larger area, values at the farthest distances became non-significant. The shape of the correlogram is, therefore, indicative of a single large patch as opposed to a gradient (Kraan et al. 2009).

Different spatial arrangements are expected to have major effects on species performance and population dynamics. For example, when conspecifics are aggregated, strong competitors perform poorly which can slow competitive exclusion, facilitating coexistence (Hart \& Marshall 2009). On the other hand, if intraspecific competition is strong, most species are likely to benefit from being randomly distributed (Turnbull et al. 2007). An aggregated distribution can also be disadvantageous if energy is a limiting factor (Heip 1975). This may help explain the random distribution of the Trondheim population since food availability is generally lower at northern 
latitudes. As the timing, duration, and composition of phytoplankton blooms are determined by temperature (e.g. Moline \& Prézelin 1996), a relationship between spatial distribution of Scrobicularia plana at a larger scale and temperature is suggested by the observed patterns.

As most natural populations are, to some extent, patchy in their spatial pattern (Levinton 1972, Heip 1975, Barry \& Dayton 1991), it is more important to determine the size of patches. Differences in patch size were observed between sites, indicating that patchiness occurs at different spatial scales. Analysis of the Wadden Sea data also provided information about the effects of temporal scale stability. Density and SAC were similar in both years, but size varied between 2008 and 2009. Variation in patch size may affect recruitment success and, ultimately, population dynamics, depending on the location of patches, as well as the dispersal ability of a species. If populations are self-recruiting from within patches, then larger patches should promote recruitment success.

\section{Are distribution patterns consistent between species?}

Comparison of spatial patterns of co-occurring bivalve species allowed us to determine if distribution patterns differ (and to what extent) between species within the same area. All bivalve species from Trondheim showed a random distribution. It is possible, however, that aggregation at an even smaller spatial scale went undetected because samples were collected at distances $>50 \mathrm{~m}$. Similar to Scrobicularia plana, Cerastoderma edule showed a highly aggregated pattern in both the Westerschelde (present study) and the Wadden Sea (Kraan et al. 2009), although with a somewhat smaller patch size. Note, however, that Kraan et al. (2009) used a cut-off point in the Moran's $I$ graphs of 0.1 instead of 0 and patch sizes of both species are very similar if a single cut-off point (0) is used. In contrast, in Minho, C. edule was characterized by a random distribution. Although both bivalve species are characteristic of the midtidal zone of the mudflats (Eltringham 1971) and are often found together in the same area (e.g. Ysebaert \& Herman 2002, Dolbeth et al. 2003), C. edule is more common in sandy areas (Bocher et al. 2007), which could help explain the observed differences. The similar distribution patterns of Abra tenuis and $S$. plana in the Westerschelde (although at different scales) can also be related to the occupation of similar niches, with both species being more abundant at southern sites and with a clear preference for muddy sediments (Bocher et al. 2007). Finally, Macoma balthica in the Wadden Sea (Kraan et al. 2009) showed a very similar pattern to the one observed in the present study for $S$. plana, but a smaller degree of aggregation in the Westerschelde. Differences may be explained by density-dependent processes as M. balthica shows higher densities at higher latitudes, while $S$. plana is more abundant in southern areas (Bocher et al. 2007).

Species composition differed between the sites studied, which probably affects Scrobicularia plana's functional role in the macrobenthic community, in particular, density dependent processes related to predator-prey interactions and intraspecific competition. For example, the oystercatcher Haematopus ostralegus, one of the main predators of $S$. plana (Hughes 1970), also feeds on other bivalves, such as Cerastoderma edule, Macoma balthica, and Mya arenaria (Zwarts \& Wanink 1993, Wanink \& Zwarts 2001). If these species are absent from the community, the predation pressure on S. plana can increase, leading to higher mortality (Holt 1977). Prey switching in oystercatchers as a response to changes in abundance has been observed (Zwarts \& Wanink 1993). As shorebirds concentrate their feeding efforts on particularly food-rich areas (e.g. van Gils et al. 2005), spatially heterogeneous predation pressure could in principle help explain patchy structures (Schneider 1992), such as those of S. plana (Jensen \& Mouritsen 1992). At this moment, we lack the data to say whether shorebird predation played such a role in the studied systems.

In contrast, the absence of other bivalve species may have a positive effect on Scrobicularia plana, as the interspecific competition for food and space can result in a decrease in growth and the overall condition of the bivalves (e.g. Kamermans et al. 1992). However, as body condition of $S$. plana in Westerschelde is better than in Minho and similar to that of Trondheim (Santos et al. 2011a), and the larger patch size and higher species diversity in Westerschelde would suggest higher interspecific competition, this does not seem to be the case. Not only do the spatial patterns of $S$. plana differ among sites, but also those of the other cooccurring bivalve species. This suggests that the spatial distributions of all the species are site-specific, which is in agreement with a previous study from Bocher et al. (2007). Nevertheless, S. plana appears, overall, to be more aggregated than other co-distributed bivalve species. 


\section{Relating distribution patterns to environmental factors}

Sediment composition is one of the factors that influences estuarine benthic assemblage structure and species distribution at local (smaller) spatial scales (Warwick et al. 1991, Ysebaert \& Herman 2002, Bocher et al. 2007, Kraan et al. 2010). In our study, the distribution of Scrobicularia plana in the Westerschelde and in Trondheim was correlated with median particle size (Table 2), confirming that a muddy sediment type is an important environmental factor determining the species' settlement patterns and subsequent survival, as shown in previous studies (Casagranda \& Boudouresque 2005, Bocher et al. 2007, Compton et al. 2009). For deposit-feeders, such as $S$. plana, the higher content of organic matter in muddy sediments (as compared to sandy sediments), is expected to provide higher quality habitat (Levinton 1972). Therefore, a coupling of feeding mode and sediment type is expected. If this is indeed the case, it suggests active habitat selection at the time of settlement with larvae actively settling in areas where the adults will do well in terms of feeding performance. Such an argument is strengthened by the observation that the spatial distributions of juvenile $S$. plana match those of the adults (Compton et al. 2009).

Active patch selection is expected when patches differ in habitat quality (Wiens 1976). The limited dispersal of adult Scrobicularia plana (Hughes 1970) implies, however, that the observed spatial patterns are unlikely to be a result of aggregative behavior of adults, but are instead caused by larval settling and post-settlement behavior (Underwood \& Chapman 1996). Species with no (or short) pelagic stages tend to have strongly aggregated distributions as a result of low mobility, while a long pelagic phase allows the population to be distributed along a larger area (Johnson et al. 2001, Shanks et al. 2003). As the pelagic stage of $S$. plana can last for several weeks (Frenkiel \& Mou za 1979), larvae should be able to disperse for distances of tens of $\mathrm{km}$ (Shanks et al. 2003), hence connecting the different patches. However, evidence is mounting that effective larval dispersal in marine populations is often limited (Cowen et al. 2000). As larvae are difficult to track directly, the extent of interpopulation connectivity can only be indirectly estimated using genetic methods. We have shown low interpopulation connectivity for $S$. plana (Santos et al. 2012), a strong indication of local larval retention.

In conclusion, the spatial distribution of Scrobicularia plana is site-specific rather than species-specific as a random distribution of $S$. plana is observed in
Norway, while populations from Portugal and the Netherlands show some degree of aggregation. Sediment composition is correlated to S. plana's distribution in 2 of the sites, suggesting that it is an important factor influencing the species distribution. Therefore, at the local scale, aggregation patterns are greatly determined by abiotic factors, particularly sediment type which acts as a cue for larval settlement.

Acknowledgements. This study was co-financed by the Portuguese Foundation for Science and Technology (FCT) and Fundo Social Europeu (POPH/FSE) through a grant awarded to S.S. (SFRH/BD/28370/2006); grants from NWO-ZKO and NAM to T.P., H.W.v.d.V., and J. van der Meer supported the SIBES-Wadden Sea efforts. Thanks to A. Santos, C. Carvalho, F. Amador, J. Smith, S. Couto, and V. Freitas for helping with sampling. Furthermore, we thank A. van Koutrik, M. Koper, S. Holthuijsen, and S. Miguel for performing the sediment analysis; and all personnel from Trondheim Biological Station (TBS - NTNU), specially J. Mork, J.-A. Sneli, J. Evertsen, and T. Bakken, for providing facilities and assistance. The 2008 and 2009 SIBES Wadden Sea campaigns were pulled off by A. Dekinga, S. Holthijsen, J. ten Horn, and others in the SIBES team, many of them helping out as volunteers. Finally, we thank J. Olsen and C. Heip for comments on earlier versions of the paper.

\section{LITERATURE CITED}

Andrew NL, Mapstone BD (1987) Sampling and the description of spatial pattern in marine ecology. Oceanogr Mar Biol Annu Rev 25:39-90

Barry JP, Dayton PK (1991) Physical heterogeneity and the organization of marine communities. Ecol Stud 86: 270-320

Benjamini Y, Hochberg Y (1995) Controlling the false discovery rate: a practical and powerful approach to multiple testing. J R Stat Soc B 57:289-300

Beukema JJ, Essink K, Michaelis H, Zwarts L (1993) Yearto-year variability in the biomass of macrobenthic animals on tidal flats of the Wadden Sea: How predictable is this food source for birds? Neth J Sea Res 31:319-330

Bijleveld AI, van Gils JA, van der Meer J, Dekinga A, Kraan C, van der Veer HW, Piersma T (2012) Designing a benthic monitoring programme with multiple conflicting objectives. Methods Ecol Evol 3:526-536

Bivand R, Anselin L, Berke O, Bernat A and others (2011) spdep: Spatial dependence: weighting schemes, statistics and models. R package version 05-31, http://cran.rproject.org/package=spdep

Bjornstad ON (2009) ncf: spatial nonparametric covariance functions. R package version 11-3, http://cran.r-project. org $/$ package $=$ ncf

Bocher P, Piersma T, Dekinga A, Kraan C and others (2007) Site- and species-specific distribution patterns of molluscs at 5 intertidal soft-sediment areas in northwest Europe during a single winter. Mar Biol 151:577-594

Campos J, Bio A, Cardoso JFMF, Dapper R, Witte JIJ, van der Veer HW (2010) Fluctuations of brown shrimp Crangon crangon abundance in the western Dutch Wadden Sea. Mar Ecol Prog Ser 405:203-219 
Casagranda C, Boudouresque CF (2005) Abundance, population structure and production of Scrobicularia plana and Abra tenuis (Bivalvia: Scrobicularidae) in a Mediterranean brackish lagoon, Lake Ichkeul, Tunisia. Int Rev Hydrobiol 90:376-391

Compton TJ, Troost TA, Drent J, Kraan C and others (2009) Repeatable sediment associations of burrowing bivalves across 6 European tidal flat systems. Mar Ecol Prog Ser 382:87-98

> Cowen RK, Lwiza KMM, Sponaugle S, Paris CB, Olson DB (2000) Connectivity of marine populations: open or closed? Science 287:857-859

de Wolf P (1989) The price of patchiness. Helgol Mar Res 43: 263-273

Dolbeth M, Pardal MA, Lillebø AI, Azeiteiro U, Marques JC (2003) Short- and long-term effects of eutrophication on the secondary production of an intertidal macrobenthic community. Mar Biol 143:1229-1238

Ellis J, Schneider D (2008) Spatial and temporal scaling in benthic ecology. J Exp Mar Biol Ecol 366:92-98

Eltringham SK (1971) Life in mud and sand. The English Universities Press, London

Ens BJ, Piersma T, Drent RH (1994) The dependence of waders and waterfowl migrating along the East Atlantic Flyway on their coastal food supplies: What is the most profitable research programme? Ophelia Suppl 6: $127-152$

> Folmer EO, Olff H, Piersma T (2010) How well do food distributions predict spatial distributions of shorebirds with different degrees of self-organization? J Anim Ecol 79: 747-756

Frenkiel L, Mouëza M (1979) Développement larvaire de deux Tellinacea, Scrobicularia plana (Semelidae) et Donax vittatus (Donacidae). Mar Biol 55:187-195

Hart SP, Marshall DJ (2009) Spatial arrangement affects population dynamics and competition independent of community composition. Ecology 90:1485-1491

Heip C (1975) On the significance of aggregation in some benthic marine invertebrates. In: Barnes $\mathrm{H}$ (ed) Proc 9th Euro Mar Biol Symp. Aberdeen University Press, Aberdeen, p 527-538

Herman PMJ, Middelburg JJ, Van de Koppel J, Heip CHR (1999) Ecology of estuarine macrobenthos. Adv Ecol Res 29:195-240

Hewitt JE, Thrush SF, Cummings VJ, Pridmore RD (1996) Matching patterns with processes: predicting the effect of size and mobility on the spatial distributions of the bivalves Macomona liliana and Austrovenus stutchburyi. Mar Ecol Prog Ser 135:57-67

Holm S (1979) A simple sequentially rejective multiple test procedure. Scand J Stat 6:65-70

Holt RD (1977) Predation, apparent competition, and the structure of prey communities. Theor Popul Biol 12: 197-229

Hughes RN (1970) Population dynamics of bivalve Scrobicularia plana (Da Costa) on an intertidal mud-flat in North Wales. J Anim Ecol 39:333-356

Jensen KT, Mouritsen KN (1992) Mass mortality in 2 common soft-bottom invertebrates, Hydrobia ulvae and Corophium volutator - the possible role of trematodes. Helgol Meersunters 46:329-339

Johnson MP, Allcock AL, Pye SE, Chambers SJ, Fitton DM (2001) The effects of dispersal mode on the spatial distribution patterns of intertidal molluscs. J Anim Ecol 70: 641-649
Kamermans P, van der Veer HW, Karczmarski L, Doeglas GW (1992) Competition in deposit- and suspension-feeding bivalves: experiments in controlled outdoor environments. J Exp Mar Biol Ecol 162:113-135

Kraan C, van der Meer J, Dekinga A, Piersma T (2009) Patchiness of macrobenthic invertebrates in homogenized intertidal habitats: hidden spatial structure at a landscape scale. Mar Ecol Prog Ser 383:211-224

> Kraan C, Aarts G, van der Meer J, Piersma T (2010) The role of environmental variables in structuring landscapescale species distributions in seafloor habitats. Ecology 91:1583-1590

Langston WJ (1986) Metals in sediments and benthic organisms in the Mersey estuary. Estuar Coast Shelf Sci 23: 239-261

Langston WJ, Burt GR, Chesman BS (2007) Feminisation of male clams Scrobicularia plana from estuaries in Southwest UK and its induction by endocrine-disrupting chemicals. Mar Ecol Prog Ser 333:173-184

> Legendre P, Fortin MJ (1989) Spatial pattern and ecological analysis. Plant Ecol 80:107-138

Legendre P, Legendre L (1998) Numerical ecology. Elsevier, Amsterdam

Leguerrier D, Niquil N, Boileau N, Rzeznik J, Sauriau PG, Le Moine O, Bacher C (2003) Numerical analysis of the food web of an intertidal mudflat ecosystem on the Atlantic coast of France. Mar Ecol Prog Ser 246:17-37

$>$ Levinton J (1972) Spatial distribution of Nucula proxima Say (Protobranchia): an experimental approach. Biol Bull 143:175-183

Maechler M, Rousseeuw P, Struyf A, Hubert M, Hornik K (2011) Cluster analysis basics and extensions. R package version 1141, http://cran.r-project.org/package=cluster

Mantel N (1967) The detection of disease clustering and a generalized regression approach. Cancer Res 27:209-220

- Martinho F, Leitão R, Neto JM, Cabral HN, Marques JC, Pardal MA (2007) The use of nursery areas by juvenile fish in a temperate estuary, Portugal. Hydrobiologia 587: 281-290

> Meire PM, Dereu JPJ, van der Meer J, Develter DWG (1989) Aggregation of littoral macrobenthic species - some theoretical and practical considerations. Hydrobiologia 175:137-148

Moline MA, Prézelin BB (1996) Long-term monitoring and analyses of physical factors regulating variability in coastal Antarctic phytoplankton biomass, in situ productivity and taxonomic composition over subseasonal, seasonal and interannual time scales. Mar Ecol Prog Ser 145: $143-160$

Moreira F (1997) The importance of shorebirds to energy fluxes in a food web of a South European estuary. Estuar Coast Shelf Sci 44:67-78

$>$ Oden NL (1984) Assessing the significance of a spatial correlogram. Geogr Anal 16:1-16

Oksanen J, Blanchet FG, Kindt R, Legendre P and others (2011) vegan: Community Ecology Package. R package version 20-0, http://cran.R-project.org/package=vegan

Rossi RE, Mulla DJ, Journel AG, Franz EH (1992) Geostatistical tools for modeling and interpreting ecological spatial dependence. Ecol Monogr 62:277-314

> Santos S, Cardoso JFMF, Carvalho C, Luttikhuizen PC, van der Veer HW (2011a) Seasonal variability in somatic and reproductive investment of the bivalve Scrobicularia plana (da Costa, 1778) along a latitudinal gradient. Estuar Coast Shelf Sci 92:19-26 
Santos S, Luttikhuizen PC, Campos J, Heip CHR, van der Veer HW (2011b) Spatial distribution patterns of the peppery furrow shell Scrobicularia plana (da Costa, 1778) along the European coast: a review. J Sea Res 66: 238-247

Santos S, Cruzeiro C, Olsen JL, van der Veer HW, Luttikhuizen PC (2012) Isolation by distance and low connectivity in the peppery furrow shell Scrobicularia plana (Bivalvia). Mar Ecol Prog Ser 462:111-124

Schneider DC (1992) Thinning and clearing of prey by predators. Am Nat 139:148-160

Shanks AL, Grantham BA, Carr MH (2003) Propagule dispersal distance and the size and spacing of marine reserves. Ecol Appl 13:159-169

Sokal RR, Oden NL (1978) Spatial autocorrelation in biology: 2. Some biological implications and 4 applications of evolutionary and ecological interest. Biol J Linn Soc 10: 229-249

Strasser M, Walensky M, Reise K (1999) Juvenile-adult distribution of the bivalve Mya arenaria on intertidal flats in the Wadden Sea: Why are there so few year classes? Helgol Mar Res 53:45-55

Sturges HA (1926) The choice of a class interval. J Am Stat Assoc 21:65-66

Tebble N (1976) British bivalve seashells: a handbook for identification. HMSO, Edinburgh

Thrush SF (1991) Spatial patterns in soft-bottom communities. Trends Ecol Evol 6:75-79

Thrush SF, Hewitt JE, Pridmore RD (1989) Patterns in the spatial arrangements of polychaetes and bivalves in intertidal sandflats. Mar Biol 102:529-535

Turnbull LA, Coomes DA, Purves DW, Rees M (2007) How spatial structure alters population and community dynamics in a natural plant community. J Ecol 95:79-89

Underwood A, Chapman M (1996) Scales of spatial patterns of distribution of intertidal invertebrates. Oecologia 107: 212-224

Underwood AJ, Chapman MG, Connell SD (2000) Observa-

Editorial responsibility: Roger Hughes,

Bangor, UK tions in ecology: you can't make progress on processes without understanding the patterns. J Exp Mar Biol Ecol 250:97-115

van de Kam J, Ens B, Piersma T, Zwarts L (2004) Shorebirds: an illustrated behavioural ecology. KNNV Publishers, Utrecht

van den Bergh GD, Boer W, de Haas H, van Weering TJCE, van Wijhe R (2003) Shallow marine tsunami deposits in Teluk Banten (NW Java, Indonesia), generated by the 1883 Krakatau eruption. Mar Geol 197:13-34

van Gils JA, Dekinga A, Spaans B, Vahl WK, Piersma T (2005) Digestive bottleneck affects foraging decisions in red knots Calidris canutus. II. Patch choice and length of working day. J Anim Ecol 74:120-130

> Wanink JH, Zwarts L (2001) Rate-maximizing optimality models predict when oystercatchers exploit a cohort of the bivalve Scrobicularia plana over a 7 -year time span. J Anim Ecol 70:150-158

Warwick RM, Goss-Custard JD, Kirby R, George CL, Pope ND, Rowden AA (1991) Static and dynamic environmental factors determining the community structure of estuarine macrobenthos in SW Britain: why is the Severn Estuary different? J Appl Ecol 28:329-345

Wickham H (2009) ggplot2: elegant graphics for data analysis. Springer, New York, NY

Wiens JA (1976) Population responses to patchy environments. Annu Rev Ecol Syst 7:81-120

> Ysebaert TJ, Herman PMJ (2002) Spatial and temporal variation in benthic macrofauna and relationships with environmental variables in an estuarine, intertidal softsediment environment. Mar Ecol Prog Ser 244:105-124

Zar JH (1996) Biostatistical analysis, 3rd edn. Prentice-Hall, Englewood Cliffs, NJ

Zwarts L, Wanink JH (1993) How the food supply harvestable by waders in the Wadden Sea depends on the variation in energy density, body weight, biomass, burying depth and behaviour of tidal-flat invertebrates. Neth J Sea Res 31:441-476

Submitted: May 23, 2012; Accepted: August 23, 2012 Proofs received from author(s): November 17, 2012 